\title{
Yeni Tip Taşlama Yönteminde Taşlama Parametrelerinin Deneysel Tasarım Yöntemi İle Yüzey Pürüzlülüğü Üzerine Etkisinin İncelenmesi
}

\author{
Oktay ADIYAMAN ${ }^{1 *}$, Fikret SÖNMEZ ${ }^{2}$ \\ ${ }^{1}$ Batman Üniversitesi, Teknoloji Fakültesi, Makine ve Imalat Mühendisliği, Batman \\ ${ }^{2}$ Karşıyaka Tüpraş Mesleki ve Teknik Anadolu Lisesi, Kocaeli \\ (ORCID: 0000-0002-2674-3836)(ORCID: 0000-0003-1718-892X)
}

\begin{abstract}
$\ddot{O} \mathbf{z}$
"İkincil eksenli düzlem yüzey taşlama yöntemi” (GMASRA) son yıllarda geliştirilmiş bir düzlem yüzey taşlama yöntemidir. Bu çalışmada, GMASRA metodu incelenmiş ve deneylerde işlemin etkilendiği parametreler olan taşlama taşı tane büyüklüğü, yanal kayma miktarı, talaş derinliği ve ikincil eksen fener mili hızı kullanılmıştır. Bu deney parametreleri 2 seviye olarak yapılandırılmış ve toplam 16 deneyden oluşan bir deney seti oluşturulmuştur. $\mathrm{Bu}$ deney setinin analizinde ve deney sonuçlarının tahmin edilmesinde faktöriyel tasarım modeli kullanılmıştır. Oluşturulan modelde 8 deney verisi kullanılmış ve parametrelerin etkinliği ile parametrelerin sonuç üzerindeki etkisi analiz edilmiştir. Aynı zamanda, modelin oluşturulmasında kullanılmayan 8 veri, modelin tahmin yeteneğinin araştırılması için kullanılmış ve deney sonuçları bu model tarafından tahmin edilmiştir. Yapılan tahminlerin yüksek tutarlılıkla $\left(\mathrm{R}^{2}=0,902\right)$ sonuçlar oluşturduğu ve bu mühendislik probleminin çözümü için uygun bir yöntem olduğu görülmüştür.
\end{abstract}

Anahtar kelimeler: Düzlem Yüzey Taşlama, Yüzey Pürüzlülüğü, Deneysel Tasarım, Optimizasyon.

\section{Investigation of the Effect of Grinding Parameters on Surface Roughness by Experimental Design Method in New Type Grinding Method}

\begin{abstract}
"Grinding Mechanism having Advanced Secondary Rotational Axis" (GMASRA) is one of the newer plane surface grinding methods that have an uncommon abrasion mechanism. In this study, the GMASRA method was investigated and in the experiments the parameters of grinding wheel mesh size, stepover, depth of cut and secondary axis spindle speed were used. These test parameters were determined as 2 levels. A total of 16 experiments were generated. A factorial design model was used to analyze this experiment set and predict the results of the experiment. In the model, 8 experimental data were used and the efficiency of the parameters and the effect of the parameters on the result were analyzed. At the same time, 8 data that were not used to generate the model were used to investigate the predictive capability of the model and the results of the experiment were estimated by this model. The predictions generated results with high consistency $\left(R^{2}=0.902\right)$ and it was found that this method was suitable for the solution of the engineering problem.
\end{abstract}

Keywords: Plane Surface Grinding, Surface Roughness, Experimental Design, Optimization.

\section{Giriş}

Taşlama işlemi, iş parçalarının istenilen şekil, ölçü ve toleranslarda elde edilmesini sağlayan önemli bir imalat yöntemidir. Bu yöntem iş parçalarının özellikle diğer işleme yöntemleriyle (tornalama, frezeleme vb.) yeterli tamlıkta ve yüzey kalitesinde üretilemediği durumlarda kullanılır [1-3]. Taşlama işleminin uzay, otomotiv, savunma sanayii, medikal parça imalatı gibi çok fazla alanda kullanımı yaygındır $[4,5]$. Ayrıca uygulama alanından ayrı olarak parçaların hassas ölçü tamlığı istenen son işlem operasyonlarında da taşlama işlemi oldukça yaygın kullanılan bir son işleme yöntemidir.

*Sorumlu yazar: oktay.adiyaman@batman.edu.tr

Geliş Tarihi: 25.03.2019, Kabul Tarihi: 05.08.2019 
Taşlama işleminde kullanılan kesme parametrelerinin (kesme hızı, ilerleme, talaş derinliği gibi) taşlama işlemi ile elde edilen sonuçlar üzerine (kuvvet, yüzey pürüzlülüğü vb) olan etkilerinin tespit edilmesi de önemli bir çalışma alanı olarak karşımıza çıkmaktadır [6,7]. Son yıllarda geliştirilmiş GMASRA düzlem yüzey taşlama yöntemi, klasik düzlem yüzey taşlama yönteminde taşın kendi ekseni etrafinda dönme hareketine ilave olarak, eklenen ikinci bir taş hareketi ile taşlama işlemi yapılmasını sağlayan taşlama yöntemidir. Bu yöntemde kullanılan kesme parametrelerinin yüzey pürüzlülüğü üzerine olan etkilerini doğru olarak tespit etmek ve herbir parametrenin hem tek başına hem de farklı kombinasyonlarla çıktı parametreleri üzerine olan etki değerlerini tespit etmek en büyük problemlerin başındadır. Bu amaçla elde edilen deney verilerini doğru bir deney tasarımı ile analiz ve deneylerden elde edilen bulgularla sonuçları yüksek güven aralığında tahmin etmek gerekliliği ortaya çıkmaktadır.

GMASRA ile ilgili farklı yönlerden bir çok araştırma yapılmış ve yapılmaktadır. GMASRA tekniğinin klasik düzlem yüzey taşlama metodu ile kıyaslanması [8], taşlama parametrelerinin yüzey pürüzlülüğü üzerine etkisinin incelenmesi [9], yöntemdeki kesme kuvveti ve motor gücünün modellenmesi [10,11], taşlama parametrelerinin etkilerinin incelenmesi [12] ve GMASRA metodunda taşlama kesme parametrelerinin Taguchi metodu ile analizi ile sistem üzerindeki en fazla etkinin tespit edilmesine yönelik çalışmalar [13] bu çalışmalardan bazılarıdır.

Optimizasyon teknikleri ve veri analiz çalışmaları deneysel yolla elde edilen verilerin yorumlanmasinda, etkin parametre/lerin tespiti ve sistemin en iyilenmesinde kullanılan tekniklerdir. İmalat süreçlerinde kesme parametrelerinin optimizasyonu ile ilgili de çalışmalar oldukça yaygındır. Baday ve arkadaşları [14] küreselleştirme 1sıl işlemi uygulanmış orta karbonlu bir çeliğin işlenmesi sonucunda meydana gelen kesme kuvvetlerini Taguchi Tasarım yöntemi ile modellemişlerdir. Ayrıca kesme kuvvetleri üzerinde kesme parametrelerin etkinliğini sinyal/gürültü oranları ile saptamışlardır. Kesme kuvvetleri üzerinde en fazla etkiye ilerleme olduğunu belirtmişlerdir.

Taşlama işlemlerinde de tüm parametrelerin farklı analiz yöntemleri ile analizi ve bu parametrelerin hem tek başına hemde birbirleri ile etkileşimli olarak taşlama işlemi üzerindeki etkisini tespit etmek oldukça önemlidir. Jae-Seab ve diğerleri [15] yüzey yanıt yöntemi kullanarak sertleştirilmiş SCM440 çeliğinin silindirik taşlanmasında yüzey pürüzlülüğü ve taşlama kuvvetlerini araştırmışlardır. Yapılan deneysel çalışmalar sonucunda yüzey yanıt yöntemi ile elde edilen matematiksel modelin imalat öncesinde uygun taşlama şartlarının belirlenmesine yardımcı olacağını belirtmişlerdir. Çetin ve arkadaşları [16] Taguchi deney tasarım yöntemi kullanılarak sementasyon çeliğinin teğetsel silindirik taşlama yöntemi ile işlenmesinde kesme parametrelerinin titreşim üzerindeki etkileri deneysel olarak incelemişlerdir. Yapılan çalışmada teğetsel silindirik taşlama yönteminin geleneksel silindirik taşlama yöntemine benzer sonuçlar verdiği ve daha pratik olduğu tespit edilmiştir. Günay ve arkadaşları [17] içten yanmalı motorlarda supap tahrik mekanizması sisteminde yer alan itici düzeneğinde kullanılan kam makaralarına bitirme işlemi olarak uygulanan taşlama prosesi sonucu elde edilen yüzey değerlerinin en iyilenmesi amacıyla $2 \mathrm{k}$ faktöriyel ( 2 seviyeli tam faktöriyel tasarım) deney tasarımı metodolojisinden faydalanmışlardır. Çalışmada; ilk olarak etkili olan değişkenler belirlenmiş, ardından yüzey pürüzlülük değerleri ve çevrim süresini eş zamanlı olarak istenen düzeyde sağlayabilecek değişken değerlerinin belirlenmesi için çok amaçli en iyileme işlemi gerçekleştirilmiş̧ir. Sonuçta en küçük yüzey pürüzlülük değerlerine ve daha düşük çevrim süresine ulaşılmıştır. Taşlama işlemi ile ilgili bir diğer optimizasyon yöntemi olarak genetik algoritma kullanılmıştır. Günay ve Mızrak genetik algoritma yöntemi kullanarak makaralar için yaptıkları çalışmada deney tasarım metodu kullanarak deneyler gerçekleştirmişler ve bu deneyler sonucunda buldukları optimum değerler ile hedeflenen yüzey pürüzlülük değerine ulaşmışlardır [18]. Çelik yaptığı çalışmada [19] 62 HRC sertlikte AISI 8620 sementasyon çeliğini silindirik taşlama işlemine tabi tutmuşlardır. Geliştirilen modelde faktörlerin etkinliği varyans analizi (ANOVA) ile tespit edilmiş ve üç farklı regresyon modeli elde edilerek, elde edilen tahmin değerleri karşılaştırılmıştır. Bu çalışma için verilen şartlarda en yüksek belirtme katsayısı $\left(\mathrm{R}^{2}\right)$, II. dereceden regresyon modeliyle Ra için \% 84,6 ve Rz için \% 89 olarak bulunmuştur. Agarval [20] düzlem yüzey taşlama işleminde talaş derinliği, tabla ilerleme hızı ve taş dokusu gibi parametrelerin yüzey pürüzlülügünün iyileştirilmesi, yüzeyde oluşan deformasyon hatalarının azaltılması ve optimum talaş kaldırma oranının elde edilmesi için eş zamanlı olarak üç amacı olan optimizasyon işlemi kullanarak her amaç için uygun taşlama işlemi faktör seviyelerini belirlemiş̧ir. Bu amaçla bir matematik model geliştirilmiş ve yüzey yanıt yöntemi kullanılarak oluşturulan çok amaçlı matematiksel modelin çözümünde genetik algoritma yönteminden faydalanılmıştır. Varma ve arkadaşları yaptıkları çalışmada [21] Inconal 800 alaşımlı çeliğin silindirik olarak taşlanmasında yüzey pürüzlülügü ve kaldırılan talaş 
miktarına etki eden taşlama parametrelerinin (iş parçası devri, talaş derinliği ve ilerleme miktarı) tahmin edilmesinde deneysel verilerle Adaptive-neuro fuzzy inference system (ANFIS), regresyon yöntemi ve yapay sinir ağları yöntemlerinin karşılaştırılmasını yapmışlardır.

GMASRA ile ilgili yapılan deneylerdeki elde edilen bulguların farklı analiz yöntemleri ile test edilmesi, sistemin kararlılığ bakımından önemlidir. Bu nedenle yapılan bu çalışmada, GMASRA üzerine yapılan deneysel çalışma [12] ile elde edilen bir kısım veri değerlendirilerek GMASRA taşlama yöntemindeki taşlama parametreleri olan taşlama taşı tane büyüklüğ̈̈, yanal kayma miktarı, talaş derinliği ve ikincil eksen fener mili hızı kullanılarak bir deney seti oluşturulmuştur. Oluşturulan bu deney setinin analizinde ve deney sonuçlarının tahmin edilmesinde faktöriyel tasarım modeli kullanılmıştır. Oluşturulan modelde 8 deney verisi kullanılmış ve parametrelerin etkinliği ile parametrelerin sonuç üzerindeki etkisi analiz edilmiştir. Aynı zamanda modelin oluşturulmasında kullanılmayan 8 veri, modelin tahmin yeteneğinin araştırılması için kullanılmış ve deney sonuçları bu model tarafindan tahmin edilmiştir.

\section{Materyal ve Metot}

Yeni bir yöntem olan GMASRA taşlama yönteminin uygulanması için tasarlanan taşlama mekanizması C-TEK marka dik işleme merkezi bir CNC tezgâha monte edilmiştir (Şekil 1).
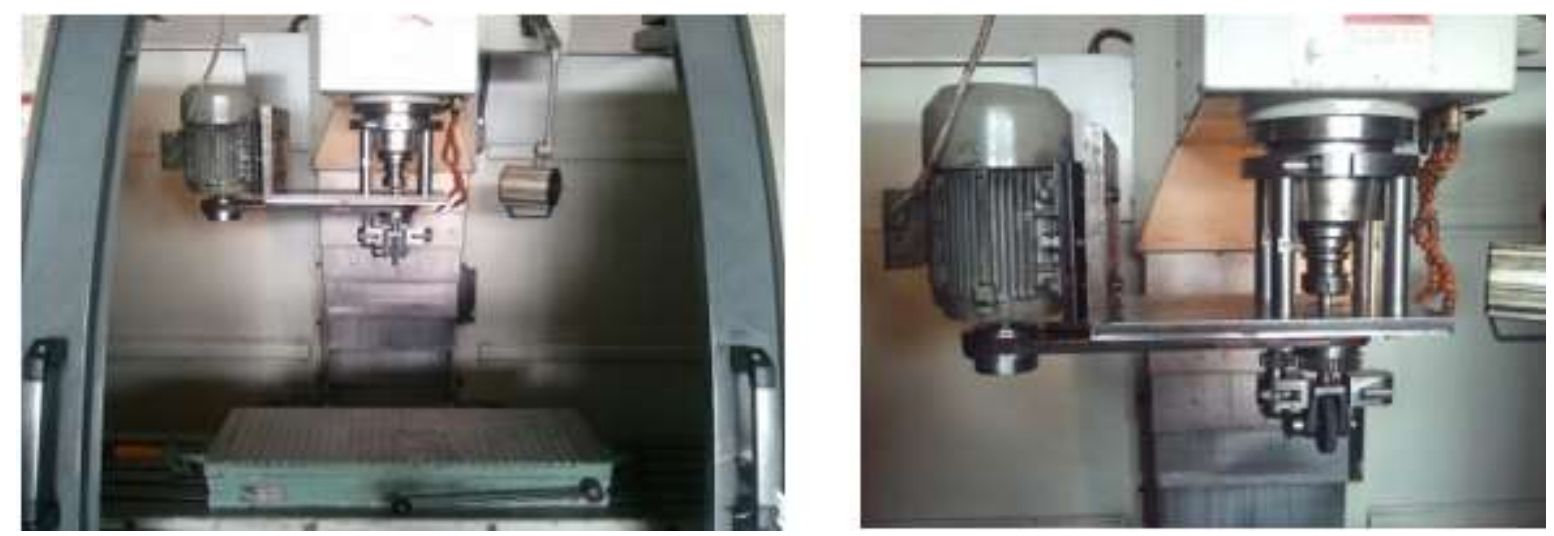

Şekil 1. GMASRA'nın CNC dik işleme merkezine montajı

\subsection{Deney Düzeneği}

Taşlama işleminin uygulanması amacıyla 100x100x20 mm (uzunluk x genişlik x kalınlık) ebatlarında St37-2 çeliği numuneler hazırlanmış ve CNC tablasına bağlı manyetik bir tabla üzerine bağlanmıştır. St37 çeliğine ait kimyasal ve mekanik özellikler Tablo 1'de gösterilmektedir.

Tablo 1. Deney numuneleri kimyasal analizi

\begin{tabular}{|c|c|c|c|c|c|c|c|c|}
\hline DIN (Eski) & DIN Yeni & SAE/AISI & \multicolumn{6}{|c|}{ Kimyasal Özellikler } \\
\hline \multirow{5}{*}{ RSt 37-2 } & \multirow{5}{*}{ S235JRG2 } & \multirow{5}{*}{ A570Gr.36 } & $\% \mathrm{C}$ & $\% M n$ & $\% \mathbf{P}$ & $\% \mathrm{~S}$ & $\% \mathrm{~N}$ & $\% \mathrm{CU}$ \\
\hline & & & 0,19 & 1,50 & 0,045 & 0,045 & 0,014 & 0,60 \\
\hline & & & \multicolumn{6}{|c|}{ Mekanik Özellikler } \\
\hline & & & $\begin{array}{c}\text { Çekme } \\
\text { Dayanımı } \\
\text { (Mpa) }\end{array}$ & $\begin{array}{c}\text { Akma Sinır } \\
\text { (Mpa) }\end{array}$ & \begin{tabular}{|l|} 
Kop \\
Uza
\end{tabular} & $\begin{array}{l}\text { na } \\
\text { nasi (\%) }\end{array}$ & Sert & $(\mathbf{H B})$ \\
\hline & & & $340-470$ & $215-235$ & & $4-26$ & & 280 \\
\hline
\end{tabular}

Numune yüzeylerinden taşlama işlemi sırasında eşit paso alınabilmesi ve yüzeylerde eşit yüzey yapısının elde edilebilmesi amacıyla ön yüzey frezeleme yapılmış, önce $63 \mathrm{~mm}$ çapında bir tarama başlığına bağlı RDMX 1604 kesici uçlar ile numunelerin üst yüzeyleri frezelenmiş ve daha sonra numuneler klasik düzlem yüzey taşlama tezgahında yüzey bütünlüğünün bozulmaması için $0,01 \mathrm{~mm}$ talaş derinliğinde ve tüm yüzeylerin temizlenebilmesi amacıyla 2 pasoda taşlanmıştır. Taşlanan 
numuneler, GMASRA taşlama mekanizmasının bağlı olduğu CNC tezgahındaki manyetik tablaya alınmışlardır. İş parçalarının taşlanması için KARBOSAN firmasından temin edilen $75 \mathrm{~mm}$ çapında, iç delik çap1 $20 \mathrm{~mm}$ ve $20 \mathrm{~mm}$ taş genişliği olan iki adet farklı tane büyüklüğünde taşlama taş1 kullanılmıştır. Taşlanmış örnek parçalarda, parça yüzeyleri Şekil 2'de gösterilmektedir.
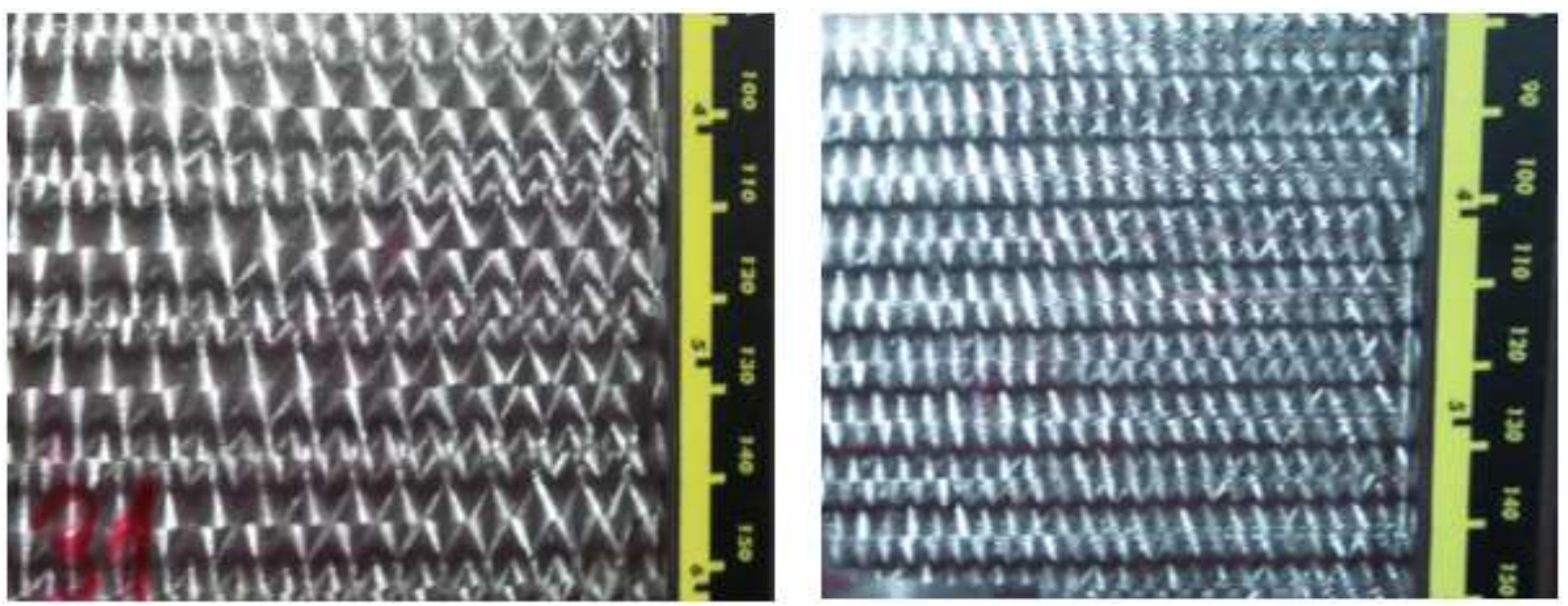

Şekil 2. Taşlanmış parçalara ait oluşan yüzey şekilleri

Yüzey pürüzlülüğünün ölçülmesinde taşın ilerleme doğrultusuna göre ölçüm yönleri belirlenmiștir. Bu ölçüm yönleri, sırasıyla taşın ilerleme yönünde, ilerleme yönüne dik yönde ve ilerleme yönüne $45^{0}$ lik açılı yönde olacak şekilde tespit edilmiştir. Seçilen her yön doğrultusunda 4 farklı ölçüm alınmış ve bu ölçümlerin aritmetik ortalaması alınarak yüzey pürüzlülük $(\mathrm{Ra})$ değerleri elde edilmiştir (Şekil 3).

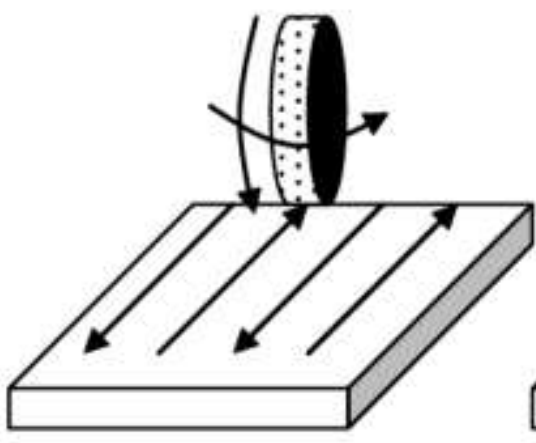

a yönü

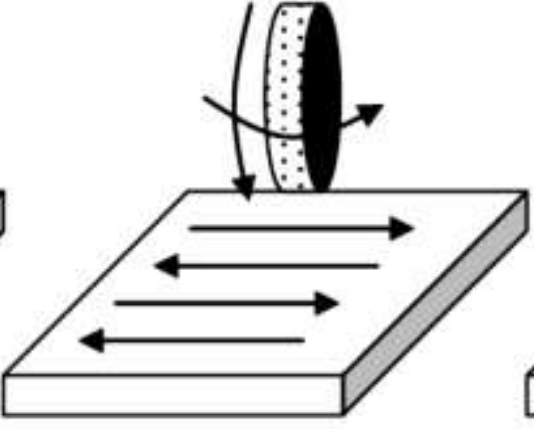

b yönï

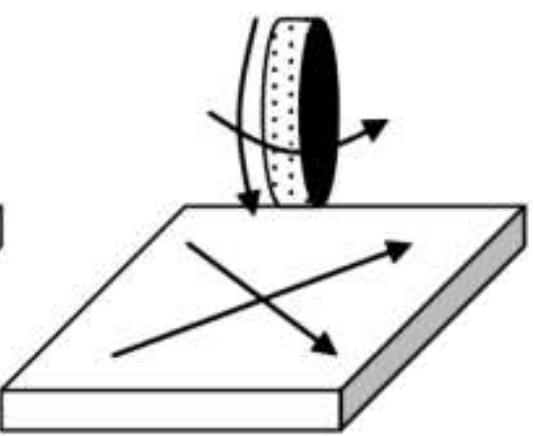

c yönü

Şekil 3. Ra ölçüm alınma yönleri [8]

\subsection{Faktöriyel Tasarım}

Deney düzeneğinde belirtildiği gibi deneylerin yapılmasında dört farklı parametre kullanılmıştır. Deneylerde kullanılan her parametre için iki adet seviye belirlenmiştir. Deney parametreleri ve parametrelere ait seviyeler Tablo 2'de görülmektedir.

Tablo 2. Faktöriyel tasarım parametreleri

\begin{tabular}{|c|c|c|c|c|c|c|c|}
\hline \multicolumn{2}{|c|}{ Taşlama Taş1 Cinsi } & \multicolumn{2}{c|}{ Yanal Kayma (mm) } & \multicolumn{2}{c|}{ Talaş Derinlĭ̆i (mm) } & \multicolumn{2}{|c|}{ İs Mili Devri (dev/dk.) } \\
\hline Seviye 1 & Seviye 2 & Seviye 1 & Seviye 2 & Seviye 1 & Seviye 2 & Seviye 1 & Seviye 2 \\
\hline EKR60K6V & EKR46K6V & 4 & 8 & 0,01 & 0,02 & 80 & 160 \\
\hline
\end{tabular}

$\mathrm{Bu}$ parametreler ve parametrelere ait seviyeler kullanıldığında toplam 16 deney gerçekleştirilmesi gerekmektedir. Toplam deney setini oluşturan 16 deneyden, bir kısmı ( 8 deney verisi) faktöriyel tasarım metodu için veri girişi olarak kullanılmıştır. Faktöriyel tasarım metodunda 
kullanılmayan veriler ( 8 deney verisi) ise oluşturulan model ile tahmin edilmeye çalışılmıştır. Deney setinde kullanılan girdi verileri ile oluşturulan model ile tahmin edilen veriler Tablo 3 'te verilmiştir.

Tablo 3. Oluşturulan model için kullanılacak veriler ve tahmin verileri

\begin{tabular}{|c|c|c|c|c|}
\hline $\begin{array}{l}\text { Zımpara Taşı } \\
\text { Cinsi }\end{array}$ & $\begin{array}{l}\text { Yanal Kayma } \\
(\mathrm{mm})\end{array}$ & $\begin{array}{l}\text { Talaş Derinliği } \\
\quad(\mathrm{mm})\end{array}$ & $\begin{array}{l}\text { İş Mili Devri } \\
\text { (dev/dk.) }\end{array}$ & $\begin{array}{c}\text { Deney Sonuçları } \\
\text { Yüzey Pürüzlülüğü (Ra) }\end{array}$ \\
\hline \multirow{8}{*}{$\begin{array}{l}\text { EKR60K6V } \\
\text { (Taş tane } \\
\text { büyüklüğü) }\end{array}$} & \multirow{4}{*}{4} & \multirow{2}{*}{0,01} & 80 & Modeli oluşturmak için kullanılacak veri \\
\hline & & & 160 & Oluşturulan model ile tahmin edilecek veri \\
\hline & & \multirow{2}{*}{0,02} & 80 & Oluşturulan model ile tahmin edilecek veri \\
\hline & & & 160 & Modeli oluşturmak için kullanılacak veri \\
\hline & \multirow{4}{*}{8} & \multirow{2}{*}{0,01} & 80 & Oluşturulan model ile tahmin edilecek veri \\
\hline & & & 160 & Modeli oluşturmak için kullanılacak veri \\
\hline & & \multirow{2}{*}{0,02} & 80 & Modeli oluşturmak için kullanılacak veri \\
\hline & & & 160 & Oluşturulan model ile tahmin edilecek veri \\
\hline \multirow{8}{*}{$\begin{array}{l}\text { EKR46K6V } \\
\text { (Taş tane } \\
\text { büyüklüğü) }\end{array}$} & \multirow{4}{*}{4} & \multirow{2}{*}{0,01} & 80 & Oluşturulan model ile tahmin edilecek veri \\
\hline & & & 160 & Modeli oluşturmak için kullanılacak veri \\
\hline & & \multirow{2}{*}{0,02} & 80 & Modeli oluşturmak için kullanılacak veri \\
\hline & & & 160 & Oluşturulan model ile tahmin edilecek veri \\
\hline & \multirow{4}{*}{8} & \multirow{2}{*}{0,01} & 80 & Modeli oluşturmak için kullanılacak veri \\
\hline & & & 160 & Oluşturulan model ile tahmin edilecek veri \\
\hline & & \multirow{2}{*}{0,02} & 80 & Oluşturulan model ile tahmin edilecek veri \\
\hline & & & 160 & Modeli oluşturmak için kullanılacak veri \\
\hline
\end{tabular}

Tablo 2'de görüldüğü gibi toplam 16 deney içerisinden 8 deney verisi modeli oluşturmak için diğer 8 deney verisi ise oluşturulan model kullanılarak deney sonuçlarının tahmin edilmesi için kullanılmıştır. Bir deneysel tasarımda doğrulama deneylerinin yapılmasındaki temel amaç, analiz basamağındaki elde edilmiş olan verilerin geçerliliğini kontrol etmek ve doğrulamaktır. Doğrulama deneyleri deney faktörlerinin ve kullanılan parametrelerin birbiri ile olan kombinasyonunu test eder. Optimize edilen koşulların doğrulanması için doğrulama deneylerinin minimum sayıda yapılmış olması gerekir [25]. Faktöriyel tasarım yöntemi ile elde edilen model Minitab 17 programı kullanılarak oluşturulmuştur. $\mathrm{Bu}$ tasarım ile yapılan incelemelerde dört giriş parametresinin yanında, parametrelerinin birbiri ile etkileşimi de analiz edilmiştir.

Yapılan çalışmada araştırma ve yayın etiğine uygun olarak tüm verilerin toplanması, değerlendirilmesi ve diğer çalışmalar yapılmış olup, çalışma ile ilgili herhangi bir kurul onayını gerektirecek bir içerik yoktur.

\section{Bulgular ve Tartışma}

\subsection{Deney Sonuçlarının Değerlendirilmesi ve Tahmin Yeterliliği}

Deney verilerinden seçilen ve modeli oluşturan 8 veri ile yapılan analizlerde, parametrelerin deney sonuçları üzerinde etkisi tespit edilmiştir. Şekil 4'te görülen Pareto grafiğinde en etkin faktörün taşlama taş1 olduğu görülmektedir. Yanal kayma miktarı ve fener mili devri parametreleri de ortalama yüzey pürüzlülüğü üzerinde belirgin etkinliğe sahiptir. Ana parametrelerden olan talaş derinliği parametresi ise deney sonuçları üzerinde sınırlı etkinlik göstermektedir. Parametrelerin birbiri ile etkileşimi sonucu ortaya çıkan $\mathrm{AB}, \mathrm{AC}$ ve $\mathrm{AD}$ faktörleri ise talaş derinliği parametresinin üstünde belirli oranda etkinliğe sahiptir. 


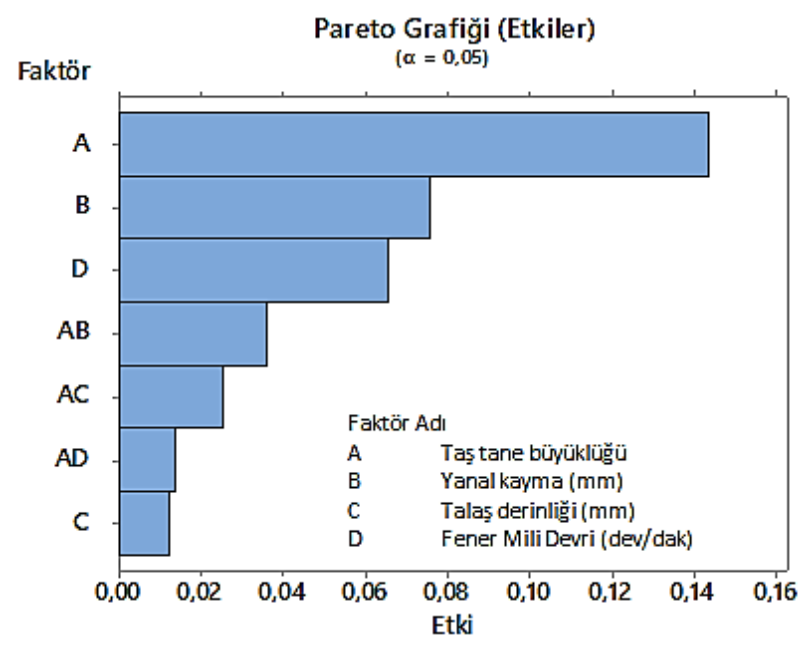

Şekil 4. Parametrelerin etkinliği için Pareto grafiği

Şekil 4'te verilen parametrelerin etkinliklerinin yanında parametrelerdeki değişimin ortalama Ra üzerindeki etkisinin de araştırılması amacı ile sonuçlar analiz edilmiş ve sonuçlar Şekil 5'te verilmiştir.

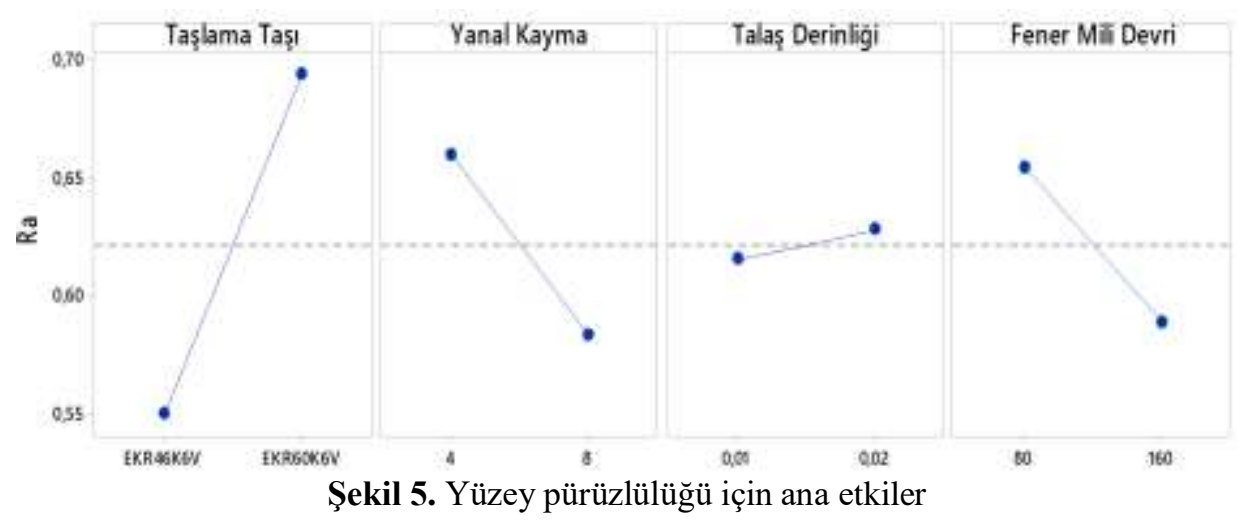

Sekil 5 incelendiğinde ana etkiyi olușturan taşlama tașı parametresinin Ra üzerindeki etkisi belirgin şekilde görülmektedir. Tane büyüklüğü 46 olan (EKR46K6V) taş ile yapılan deneylerde düşük Ra değerine $(0,494 \mu \mathrm{m})$ ulaşılmaktadır. Taş tane büyüklüğü değiştiğinde (EKR60K6V), tane büyüklüğü 60 ise yüzey pürüzlülüğü değeri ortalama \%25-30 oranında $(0,690 \mu \mathrm{m})$ artmaktadır. Taşlama taşlarındaki tane büyüklüğü taş üzerindeki taneciklerin boyutları ile ilgilidir. Genel kural olarak yumuşak malzemelerde büyük tane boyutu ve daha sert sınıf taşlama taşı kullanılırken sert malzemelerin taşlanmasında küçük tane boyutu ve yumuşak sınıf taşlama taşı kullanılır [29]. Çalışmada St37-2 malzeme numuneler taşlandığ 1 ve bu malzemenin de yumuşak olması nedeniyle buna uygun olarak EKR46K6V taş daha uygun bir taş cinsidir. Burada düşük Ra değeri elde edilmesinde malzemeye uygun taş cinsinin etkili olduğu değerlendirilmektedir.

Yanal kayma miktarının değișiminde artan yanal kayma miktarı Ra üzerinde olumlu yönde azalma meydana getirmektedir. Bunun nedeni ile ilgili ilk olarak, çalışmada $20 \mathrm{~mm}$ kalınlığında taş kullanıldığı daha önce belirtilmişti. Burada yanal kayma miktarının artması ile kaldırılan talaş hacminin arttığı ve buna bağlı olarak Ra'da artmanın meydana gelmesi gerektiği düşünülebilir. Ancak taşlama mekaniği incelendiğinde taşta bulunan aşındırıcı taneciğin parça üzerinde kazıma yaptığı ve dışarı doğru bir yığılma meydana getirdiği çeşitli çalışmalarda belirtilmiştir [26,27]. Oluşan yığılmaların ve yüzeyde aşındırıcı taneciklerin oluşturduğu oyukların hem Ra değerlerinde hem de taşlama kuvvetinde artışa neden olduğu [27] bilinmektedir. Bazı çalışmalarda körelmiş bir taşın bir dereceye kadar daha düşük yüzey pürüzlülükleri de oluşturduğu da ayrıca gözlenmiştir [24]. Körelmiş taşın parça yüzeyinde oyukları ve yığılmaları önlediği ve bir bakıma silici uç gibi davrandığını ve böylece buna neden olduğunu düşünmekteyiz. Tüm bunlardan hareketle yaptığımız bu çalışmada, yanal kayma miktarının düşük olduğu durumlarda parça yüzeyinde taşın daha az miktarda yan tarafa kayması ve bunun 
sonucunda da daha fazla taneciğin aynı yüzey üzerinde daha fazla oyuk ve yığılma meydana getirmesi nedeniyle Ra değerlerinde artı̧̧ olduğu düşünülmektedir. İkinci olarak, GMASRA ile ilgili yapılan önceki çalışmalarda $[8,28]$ eklenen fener mili hareketi ile klasik düzlem yüzey taşlama metoduna göre daha düşük Ra değerleri elde edildiği tespit edilmiştir. Bunun nedeni olarak, GMASRA yöntemindeki fener mili hareketi ile klasik taşlama yönteminde oluşan taş üzerindeki hasarların ve profil değişimlerinin GMASRA yönteminde yüzeye yansımamamasından kaynaklandığı düşünülmektedir. Bu nedenle yanal kayma miktarının artması ile her ne kadar kaldırılan talaş miktarı ve buna bağlı olarak ta $\mathrm{Ra}$ değerlerinin artması gerektiği düşünülse de fener mili dönme hareketi ile bu olumsuzluk giderilmektedir. Yüksek yanal kayma miktarında düşük yanal kayma miktarından daha düşük Ra değeri oluşması da yüksek yanal kayma miktarında daha az aşındırıcı taneciğin yüzeyde hasar ve taş profili oluşturması nedeniyle oluşturduğu değerlendirilmektedir.

Talaşlı imalat işlemlerinde ve taşlama işlemlerinde genel olarak talaş miktarındaki artış Ra üzerinde olumsuz yönde artışa neden olmaktadır [3, 21, 22, 23]. Gopan [3] talaş derinliğinin yüzey pürüzlülügü üzerine etkisini \%37.55 olarak, taş hızının etkisini \%37,67 olarak ve ilerlemenin etkisini ise \%24.78 olarak tespit etmiştir. Puerto ve arkadaşları [24] talaş derinliğinin artışına bağlı olarak kaldırılan talaş miktarının artışına bağlı olarak taşın belli bir aşınmaya kadar Ra'da artma meydana geldiğini ancak taşın aşınması sonrası Ra'da yatay bir seyir görüldügünü tespit etmiştir. Bu çalışmadaki deney setinde de sonuç genel talaşlı imalat prensiplerine uygun şekillenmektedir. Bununla birlikte talaş derinliği parametresindeki değişim, sonuç üzerinde oldukça sınırlı etkiye sahiptir. Artan talaş derinliği Ra üzerinde yalnızca $\% 2$ oranında bir artışa sebep olmaktadır. Talaş derinliğinin daha da yükseltilmesi ile Ra üzerinde daha düşük Ra değerleri elde edilmesine yönelik bir eğilim olacağı ve $\% 2$ olan bu etkinin daha da yüksek olacağı değerlendirilmektedir. Fener mili devrinin değişimi değerlendirildiğinde ise artan fener mili devri Ra değerlerini azaltmaktadır. Bu durum GMASRA yönteminin daha önceki çalışmalarında da benzer şekildedir [12,13]. GMASRA yönteminde iki farklı taş dönme hareketi vardır ve her iki yöndeki dönme hareketleri taşlama işlemindeki ideal kesme hızı şartlarında olmalıdır. Taşlamada ideal kesme hızı 25-30 m/sn şeklindedir [13]. GMASRA yönteminde eklenen ikinci dönme hareketi, prototip çalışması olması dolayısıyla düşük devirlerde tutulmuştur. En düşük Ra değerleri de uygun diğer taşlama parametreleri ile birlikte ideal kesme hızlarındaki taş devirlerinde elde edilmektedir. Çalışmadaki 80 ve 160 dev/dak fener mili devirleri ideal kesme değerlerine oldukça uzak değerlerdir. Nitekim çalışmalarda bu devir sayısı arttıkça daha düşük Ra değerleri elde edildiği görülmektedir. Bu çalışmada da 160 dev/dak devirde daha yüksek $\mathrm{Ra}$ değerleri elde edilmesinin nedeninin ideal kesme hızı değerlerine daha yakın değer olmasından kaynaklandığı değerlendirilmektedir.

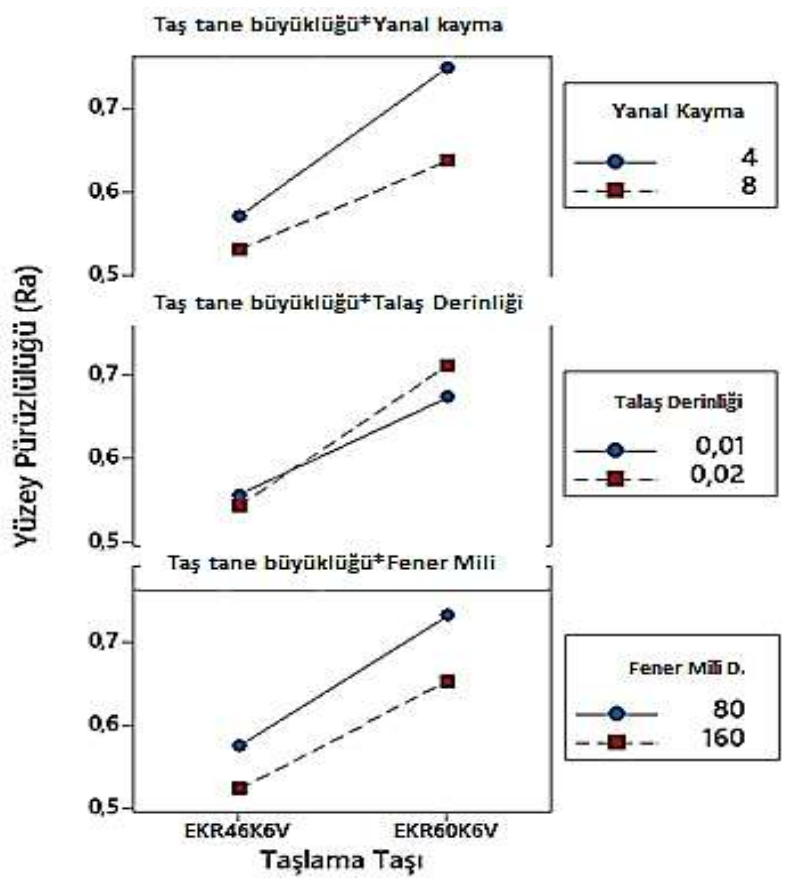

Şekil 6. Parametrelerin ilişkileri 
Taşlama parametreleri olan yanal kayma miktarı, fener mili devri ve talaş derinliği miktarının taş tane büyüklüğü ile ilişkileri incelendiğinde (şekil 6), değişen taşlama parametrelerinin her iki taş tane büyüklüğü için de benzer değişikliklere neden olduğu görülmektedir. Burada fener mili devrinin artması ile Ra'nın azaldığı görülmektedir. Bu durum literatüre [3, 21, 22] paralel durum arzetmektedir. Ayrıca bu durum taşlama parametrelerinin, kullanılan taşlama taşı tane büyüklüğünden bağımsız şekilde sonuç ürettiğini de göstermektedir. Her üç grafikte de sonuçların paralel yapıda olduğu görülmektedir. Bununla birlikte taş tane büyüklüğü ve talaş derinliği birlikte değerlendirildiğinde oluşan eğriler birbirini kesmektedir. Bu durum parametrelerin birbirini etkilediği göstermektedir ancak grafikteki benzer açılar bu durumun sınırlı olduğunu göstermektedir.

\section{2. Modelin Tahmin Yeterliliğinin Değerlendirilmesi}

Oluşturulan model ile elde edilen çıkarımlar sonrası, modelin tahmin yeteneği araştırılmıştır. Bu amaçla toplam deney seti olan 16 deneyden, modeli oluşturmak için kullanılmayan 8 veri seçilmiştir. Bu veriler, oluşturulan model ile elde edilen tahmin sonuçları ile karşılaştırılmıştır. Tablo 4'te deneysel çalışma sonucunda elde edilen deney sonuçları ile oluşturulan model tarafindan hesaplanan tahmin sonuçları görülmektedir.

Tablo 4. Deney sonuçları ve tahmin sonuçları

\begin{tabular}{|c|c|c|c|c|c|}
\hline \multirow{2}{*}{$\begin{array}{l}\text { Zımpara Taşı } \\
\text { Cinsi }\end{array}$} & \multirow{2}{*}{$\begin{array}{c}\text { Yanal Kayma } \\
(\mathrm{mm})\end{array}$} & \multirow{2}{*}{$\begin{array}{l}\text { Talaş Derinliği } \\
(\mathrm{mm})\end{array}$} & \multirow{2}{*}{$\begin{array}{l}\text { İş Mili Devri } \\
\text { (dev/dk.) }\end{array}$} & \multicolumn{2}{|c|}{ Yüzey Pürüzlülüğü (Ra) $\mu \mathrm{m}$} \\
\hline & & & & Deney Sonuçları & Tahmin Sonuçları \\
\hline \multirow{4}{*}{ EKR60K6V } & \multirow{2}{*}{4} & 0,01 & 160 & 0,6902 & 0,7092 \\
\hline & & 0,02 & 80 & 0,8077 & 0,8149 \\
\hline & \multirow{2}{*}{8} & 0,01 & 80 & 0,6580 & 0,6754 \\
\hline & & 0,02 & 160 & 0,6165 & 0,6580 \\
\hline \multirow{4}{*}{ EKR46K6V } & \multirow{2}{*}{4} & 0,01 & 80 & 0,6017 & 0,5556 \\
\hline & & 0,02 & 160 & 0,5370 & 0,5346 \\
\hline & \multirow{2}{*}{8} & 0,01 & 160 & 0,5100 & 0,4619 \\
\hline & & 0,02 & 80 & 0,5488 & 0,5977 \\
\hline
\end{tabular}

Deneysel veriler ile tahmin edilen verilerin değerlendirilmesi için elde edilen bu değerler Şekil 7'de grafik olarak verilmiştir.

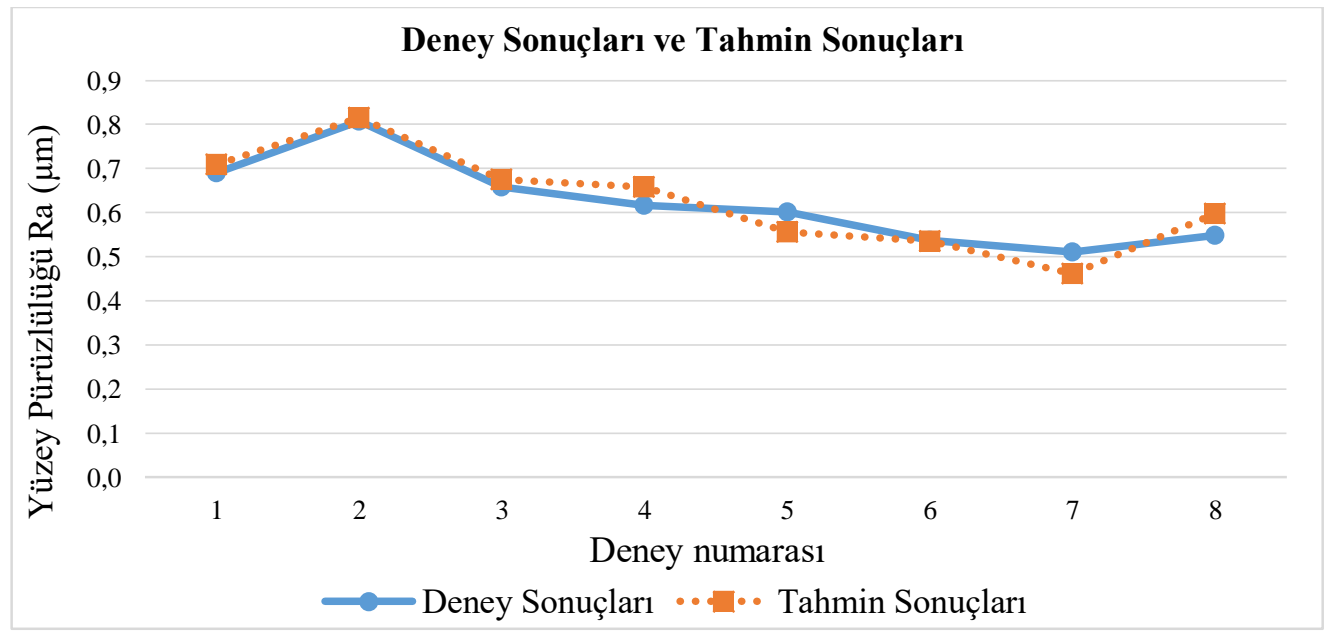

Şekil 7. Deney sonuçları ve tahmin sonuçları

Şekil 7 incelendiğinde deney sonuçlarının oluşturulan, faktöriyel tasarım modeli tarafından tahmin edilen sonuçlarla büyük oranda örtüştüğü görülmektedir. Bu deneysel çalışma kullanılarak oluşturulan modelin tahmin yeteneğinin regresyon analizi ile değerlendirilmesi sonucu elde edilen $\mathrm{R}^{2}$ 
değeri 0,902 olarak şekillenmektedir. Yüksek $\mathrm{R}^{2}$ oranı ve yüksek tutarlılıkta tahmin yeteneği bu problemin çözümü için faktöriyel tasarımın uygun bir yöntem olduğunu ortaya koymaktadır.

\section{Sonuç ve Öneriler}

“İkincil eksenli düzlem yüzey taşlama yöntemi” (GMASRA) ile farklı taşlama parametreleri ile taşlanmış parçalar üzerinden ölçülen Ra değerlerini etkileyen taşlama parametrelerinin belirlenmesine yönelik deneysel tasarım metodu ile modellenmesi ve elde edilen modelin tahmin yeteneğinin test edilmesi amacıyla yapılan bu çalışmada aşağıdaki sonuçlar elde edilmiştir.

- Toplam 16 deneyden oluşan bu deney setinin 8 deney kullanarak modellenmesi mümkündür.

- Deney çıktısı olarak değerlendirilen Ra değerlerinin oluşmasında en etkin parametre taş tane büyüklüğünün niteliğidir. EKR60K6V model (taş tane büyüklüğü 60) taş daha yüksek Ra değerleri üretirken, EKR46K6V model (taş tane büyüklüğü 46) taşlama taşı, Ra açısından yaklaşık \%25 daha düşük Ra değeri üretmektedir.

- Yanal kayma ve fener mili devri değerlerinin artması Ra değerlerini azaltırken talaş derinliğinin azalması Ra değerlerini azaltmaktadır. Bununla birlikte talaș derinliği parametresinin değișimi yalnızca \%2 oranında bir değişim oluşturmaktadır.

- Oluşturulan faktöriyel tasarım modelinin ürettiği tahmin sonuçları ile yapılan deneysel sonuçlar karşılaştırıldığında yüksek tutarlılık $\left(\mathrm{R}^{2}=0,902\right)$ gözlenmiştir. Bu durumda kullanılan bu yöntemin gerek parametrelerin analizinde gerekse doğru tahminler oluşturması açısından kullanılabilir olduğunu göstermektedir.

\section{Yazarların Katkısı}

Bu makalede yazar olarak isimleri geçen Oktay Adıyaman, makalenin taşlama işlemleri ile ilgili olarak prototip çalışmasının tasarımı, imalatı, montajı ve bu prototip ile deney numunelerinin farklı parametrelere göre düzlem yüzey taşlama işlemlerinin yapılması, deneysel verilerin elde edilmesi işlemlerini yapmıştır. İkinci yazar Fikret Sönmez ise deneysel olarak elde edilen tüm veriler ile ilgili olarak verilerin analizi, deneysel tasarım işlemleri ve modellemelerin yapılması işlemlerini icra etmiştir.

\section{Çıkar Çatışması Beyanı}

Yazarlar arasında herhangi bir çıkar çatışması bulunmamaktadır.

\section{Araştırma ve Yayın Etiği Beyanı}

Yapılan çalışmada, araştırma ve yayın etiğine uyulmuştur.

\section{Kaynaklar}

[1] Tonshoff H. K. Karpuschewski B., Mandrysch T. 1998. Grinding Process Achievements and Their Consequences on Machine Tools Chalenges and Opportunities. Annals of CIRP, 47: 651668.

[2] Malkin S., Gao C. 2008. Grinding Technology-Theory and Applications of Machining with abrasives. Industrial Press, New York.

[3] Gopan V., Wins K.L.D., Surendran A. 2018. Integrated ANN-GA Approach for Predictive Modeling and Optimization of Grinding Parameters with Surface Roughness as the Response. Materials Today: Proceedings, 5 (5): 12133-12141.

[4] Demir H., Güllü A. 1999. Silindirik Taşlamada Yüzey Pürüzlülüğü ve Taşlama Oranı İlişkisinin Araştırılması. Z.K.Ü. Karabük Teknik Eğitim Fakültesi Teknoloji, 1 (2): 151-167.

[5] Tonshoff H.K., Friemuth T., Becker J.C. 2002. Process Monitoring in Grinding. Annals of CIRP, 51: 551-571. 
[6] Watanabe N., Yoshioka H., Shinno H. 2007. Development of a Novel Vertical CNC MultipleFunction Integrated Grinding Machine. Journal of Advanced Mechanical Design, System and Manufacturing, 1 (3).

[7] Andrew W., Al-Mokhtar O., Mohamed R.B. 2013. Application of shallow circumferential grooved wheels to creep-feed grinding. Journal of Materials Processing Technology, 213 (5): 700706.

[8] Adıyaman O., Savaş V. 2014. İkincil Dönel Eksenli ile Klasik Düzlem Yüzey Taşlama Mekanizmalarının Deneysel Araştırılması. Makine Teknolojileri Elektronik Dergisi, 11 (4): 2136.

[9] Adıyaman O. 2016. İkincil Dönel Eksenli ile Klasik Düzlem Yüzey Taşlama Mekanizmasında Kesme Parametrelerinin Yüzey Pürüzlülügüne Etkisinin Deneysel İncelenmesi. Technological Applied Sciences, 11 (1): 10-23.

[10] Demir Z., Adıyaman O., Savaş V. 2016. İkincil Dönel Eksenli Taşlamada Taşlama Kuvvetinin Matematiksel Modelleme ve Matlab Programı Kullanılarak Araştırılması. 7th International Symposium on Machining, November 3-5, Marmara University, Istanbul.

[11] Adıyaman O., Demir Z., Savaş V. 2016. Matematiksel Modelleme Yöntemiyle İkincil Dönel Eksenli Taşlamada Motor Gücünün Hesaplanmasının Araştırılması. 7th International Symposium on Machining, November 3-5, Marmara University, Istanbul.

[12] Adıyaman O., Savaş V. 2017. Yeni bir tip düzlem yüzey taşlama mekanizması ile kesme parametrelerinin yüzey pürüzlülüğüne (Ra) etkisinin araştırılması. Politeknik Dergisi, 20 (4): 815825.

[13] Adıyaman O., Savaş V., Baday Ş. 2018. Improvement of grinding performance and investigation of cutting parameters using a grinding mechanism with secondary rotational axis. The International Journal of Advanced Manufacturing Technology, 99 (9-12): 2231-2244.

[14] Baday Ş., Başak H., Sönmez F. 2017. The Assessment of Cutting Force with Taguchi Design in Medium Carbon Steel-Applied Spheroidization Heat Treatment. Measurement and Control, 50 (4): 89-96.

[15] Jae-Seob K., Sung-Bo S., Yeong-Deug J. 2006. An Analysis of Grinding Power and Surface Roughness in External Cylindrical Grinding of Hardened Scm440 Steel Using The Response Surface Method. International Journal of Machine Tools \& Manufacture, 46: 304-312.

[16] Çetin Ö., Ballıkaya H., Altuğ M., Savaş V., Sağlam M. 2018. Teğetsel Silindirik Taşlama Yönteminde İşleme Parametrelerinin Titreşim Üzerindeki Etkilerinin Araştırılması. Fırat Üniversitesi Mühendislik Bilimleri Dergisi, 30 (1): 311-317.

[17] Gunay E., Yurdakul M., Ic Y.T., Mizrak H.V., Gunes S. 2018. Optimization of the Factors That are Critical in External Surface Grinding of Roller Followers Using Design of Experiments. Journal of Polytechnic-Politeknik Dergisi, 21(1): 27-37.

[18] Mızrak H.V. 2016. Makara Dış Çap Taşlamada Gerekli Yüzey Pürüzlülük Değerinin Elde Edilmesi İçin Deney Tasarım Yöntemi ile Optimum Taşlama Parametrelerinin Belirlenmesi. Yüksek Lisans Tezi, Gazi Üniversitesi, Fen Bilimleri Enstitüsü, Ankara.

[19] Çelik L. 2010. Taşlama İşleminde Titreşimin İzlenmesi ve Yüzey Pürüzlülüğünün Regresyonla Modellenmesi. Doktora Tezi, Selçuk Üniversitesi, Fen Bilimleri Enstitüsü, Konya.

[20] Agarwal S., 2016. Optimizing Machining Parameters to Combine High Productivity with High Surface Integrity in Grinding Silicon Carbide Ceramics. Ceramics International, 42 (5): 62446262.

[21] Varma N.S.K., Varma I.R.P.K., Rajesh S., Raju K.S.R., Raju V.M.K. 2018. Prediction of Surface Roughness and Mrr in Grinding Process on Inconel 800 Alloy Using Neural Networks and ANFIS. Materials Today: Proceedings, 5 (2): 5445-5451.

[22] Varma N.S.K., Rajesh S., Raju K.S.R., Raju V.M.K. 2017. Neural Network and Fuzzy Logic based prediction of Surface Roughness and MRR in Cylindrical Grinding Process. Materials Today: Proceedings, 4 (8): 8134-8141.

[23] Onwuka G., Abou-El-Hossein K. 2016. Surface roughness in ultra-high precision grinding of BK7. Procedia CIRP, 45: 143-146.

[24] Puerto P., Fernández, R., Madariaga J., Arana J., Gallego I. 2013. Evolution of surface roughness in grinding and its relationship with the dressing parameters and the radial wear. Procedia Engineering, 63: 174-182. 
[25] Roy R.K. 1990. A Primer On The Taguchi Method, Competitive Manufacturing Series. Van Nostrand Reinhold, New York.

[26] Chen X., Rowe W.B. 1996. Analysis and Simulation of the Grinding Process. Part II: Mechanics of Grinding, International Journal of Machine Tools \& Manufacture, 36: 883-896.

[27] Zhang Y., Li C., Ji H., Yang X., Yang M., Jia D., Zhang X., Li R., Wang J. 2017. Analysis of grinding mechanics and improved predictive force model based on material-removal and plasticstacking mechanisms. Int J Mach Tools Manuf., 122:81-97.

[28] Adıyaman O., Savaş V. 2014. İkincil Dönel Eksenli ile Klasik Düzlem Yüzey Taşlama Mekanizmalarının Deneysel Araştırılması. Makine Teknolojileri Elektronik Dergisi, 11 (4): 2136.

[29] Groover M.P. 2016. Modern İmalatın Prensipleri. Nobel Yayıncılık, Ankara. 